\title{
On the Innovation of Library Management by Way of Knowledge Management
}

\author{
Jin Chunfu \\ Library Section, Jilin Business and Technology College \\ chunfu1234@sina.con
}

\begin{abstract}
When it comes to library, most people have the impression that its The managing pattern is dull and backward and it cannot meet the user's need. As the rapid development of modern network, online reading and online surfing become more and more popular, so it is necessary to innovate the managing pattern with the aim to change the backward managing pattern into modern resource management by way of knowledge management and finnally to improve the developing potential of library.
\end{abstract}

Index Terms - library, knowledge management, innovation

Present society is stepping into the era of knowledge economy, and knowledge is the source of power in the development of social productive forces. For the realization of self-survival and self-development, impoving their competitive ability in innovative ways has become the industry to maintain the vitality and sustainable development means. In modern society, in order to enhance economy, traditional development mode of operation has been replaced with knowledge innovation. At the same time, as a management method of knowledge, knowledge management has emerged. Through the integration of resources, with the development of economy and people's increasing demands on living standard, and by means of properly managing innovation methods, people can make a better use of the knowledge and can finally make a decision or achieve success on the basis of it. By knowledge management, that is, the systematic management of knowledge integration, people can develop their ability on searching, integrating and utilizing of the prior knowledge, improve the work efficiency, and become more competitive in life or in work. Knowledge management has been applied to all fields, and through the knowledge management for library management, people can achieve knowledge and information integration, improve the traditional library management. Through the innovation of knowledge management and refreshing the knowledge of library information, library can meet customers' increasing demands for knowledge. With the development of science, library is confronted with chances as well as challenges. Keeping up with these developments, library personels are looking for new methods on the innovation of knowledge management to realize to serve the public, satisfy the people's spiritual needs, and finally achieve the goal of improvement of the national quality.

\section{A Summary of Knowledge Management}

In different periods and in different fields, knowledge management coveys a different definition. Usually the knowledge management refers to a way by which enterprises are provided with knowledge, and accordingly obtain economic benefits. In the traditional library management, knowledge management is the knowledge and resource management, which advocates people-oriented, makes innovation as the goal and takes the knowledge as the foundation for the development by using the knowledge collection, knowledge collation, knowledge application and dissemination, and eventually creates values.

\section{Present Situation on Library Management}

China's economy is developing rapidly, and also, information technology is varying from minute to minute. In order to meet the needs of all walks of life, the theory of knowledge management is required to be improved and innovated. The library, based on the development and dissemination of knowledge, takes the knowledge spreading, knowledge application as its responsibility and plays a very important role in the economic and cultural construction of our country. Therefore, knowledge management is a product of the development of the information age, by which the library can improve their competition ability and realize continuous developing management. Consequenttly the importance of the library management is no longer a traditional literature resources, but as human-oriented communication and analysis of resource management.

There are a lot of problems on China's present library management. The structural system, the personnel system and the management concept can not coordinate with each other. The library is restricted by many factors and faces many difficulties in the process of the innovation. The management mode is backward, human resources has not been carried out, personel subjective initiatives are neglected and so the work efficiency is greatly reduced. Therefore library can not transfer and share information resources with the users well. The present problems on the library management need to be solved and integrated. Only by the innovation on the management of library knowledge, can the library improve the comprehensive abilities to meet the needs of the society and offer better service to customers.

\section{General Summary of Knowledge Management}

Knowledge management in a library means managing a library with the approach of knowledge management. Compared with tradtional managing pattern, knowledge management system has more implications. By this way of management, people can use the infromation and materials 
easier, and it can meet the needs of the users in terms of service, techniqus, circualtion, which can fully fulfil library's social funcations such as popularizing culture and knowledge to the mess and in this way the library can play important role in society.

\section{Innovation of Knowledge Management}

The Innovation of knowledge management refers to the integretion of all kinds of information resources by way of knowledge management. The process of intergration and reallocatioin of kinds of information resources is the imporatant approach to completing the construction of library and keeping the sustainable development of library.

In order to meet people's need for information and better service, some important theories of knowledge management should be applied in the process of liabray knowledge management, which can make the resource allocation more reaonsable and the function more efficient. The followings are some main contents and approches.

\subsection{Innovative contents of knowledge management}

With the combination of actual situation of library and based on the social economic development as well as socail progress, some ideas should be innovative which include the integration of literatures and working staff. After scuh integration, the library can satisfy user's needs and promote the function of library and finally realize the aim of improving all people's overall quality.

Modern society is one with the characteristic of rapid development of information. People have made great progress in awareness and their horizon has been broadened. Therefore, the concept of liabary management should adapt to the rapid development of information, combine the concept of knowledge management to change the concept of library service.

\section{2 innovation of working staff}

The trational library managing target is inner circle scuh as working staff, literatures and facilities. These managing targets for a long time are in the state of being static except some accumulaiton of literature or shift of working staff. Unchangable service attitude, stable working situation, and old-fashioned resources attritue to the backwardness of library managing level. All these factors indicate that the present situation can meet the need of users.

Library is acomprehensive institute which covers all kinds of resources, so peole cannot only focus on its resources to manage. Personnel resource management and stuff resource management are equal important. So the managing target is becoming more and more complicated with the features of increasing and changing managing target. It is imperative to understand who are the managing target and based on their acutal situation some better managing appraoches should be adpoted to fulfil the aim of total management.

\subsection{Innovation of managing pattern}

The present managing pattern of library is on the preliminary stage, which can satisfy the need of social development. So in order to meet the need of social development, the innovation of managing pattern is on the agenda.

As is discussed above, the traditional library management only focuses on literature, that is to say, focusing on the borrowing and returning of books by way of manual operation, and this kind of management cannot meet the user's need any more. If the situation were allowed to continue and without the better exploration and application of the library, the foreseeing result of the library would be kicked off by market competition. Hence, a new kind of managing patter is badly needed.

The new kind of managing pattern would in one way take regualtion of the knowledge as the core, and advocate the systematic operation by way of encouraging experts to engage in library management by which can promote the fame of library. In another, the training and cultivation of working staff should be enhanced by unifying the opreation rules and service regulation. Thus the cooperation and operation of library would be maximized.

\subsection{Innovation of managing service}

If the traditonal method of library management cannot be changed and innovated, the developing trend of library would become blocking and the scope of servce traget would become narrower and narrower. Furtheremore, the applying rate of the library would become lower and lower, which would result in the low economic benefits of the library.

The innovation of the managing pattern mainly concentrates on the serving target and takes the user's need as core by way of combination of user's need with the library's available resources as well as bridging the different user's reading environment to satisfy the user's individual demands. By doing so the resources of library can used more efficiently and improve the economic benefit. As a result, the competive power has been improved and prepared for sustainable development.

\subsection{Innovation of managing content}

As far as innovation of managing content, the main practice is to create new manging content, which means the combination of library of knowledge management and human resource and the integration of innovation of knowledge, popularization of information and service of working staff. The other way is to analyze the actual problem met by the people in the process of working and track down the proper solutions.

\subsection{Innovation of managing knowledge}

The innovation of managing knowledge is the center of innovation of library. Knowledge, as the basis of library's existence, has a very important role. The key aspect of innovation of managing knowledge lies in the bridging of communicative platform for the knowledge and knowledge seekers with aim to supply better service for the user's need of knowledge and their application of knowledge. Only in this 
way can we attain the goal of innovation of managing knowledge

\subsection{Approaches to innovation of library's knowledge management}

It is self-evident now that innovation of library management is a must and the way to innovation is integration and combination of the network resources with the aim to explore and reuse these resources. Thereby the library will kick off its old-fashoined way of management and become the platform of knowledge innovation. The innovative library would set up information center, information website to serve the superior users such as government, scientific researching institutes and hi-tech enterprises by way of online information inquiry and guiding. All these efforts contribute to the library's innovative ability and adapt to the modern economic developing pattern.

\section{The Importance of Knowledge Management in Library Development}

Library is the result of human civilization and the product of social development. Human's social progress and development need the library. Knowledge management plays important role in the construction and development of library in our country. The combination of knowledge management and library operation, the effective function of knowledge management in library can make our library management develop rapidly. Knowledge management emphasizes on personnel training, and it includes series of management activities centering on innovation. With the fast development of our knowledge economy, the pattern of knowledge management will make library be used more and more widely. As treasury of knowledge and civilization, library not only bears the responsibility of inheriting human civilization and promoting human development, but also needs to keep innovating and sustainable development.

Library is the institution containing all traditional culture and collecting information. The function of library is related to knowledge. The service of libraryis to satisfy people's need to information. By scientific methods, knowledge management connects knowledge and people closely and constructs a platform between them to provide the readers with information and to create new knowledge for society or achieve new economic benefit. This can satisfy not only the readers' need, but also the society's requirements.

Nowadays, it is a developing society, it is an economic society as well. As a service institution, library is facing more severe competition. In order to survive and develop, library has to promote itself through continuous study and reform. Knowledge management is even thein formation course in some foreign universities, which trains a lot of knowledge management personnel. Our library should learn from the advanced management of our country and foreign countries and should make good use of library resources to make more progress and innovation in library management. Knowledge management can make the management and construction of library have a good development future.

\section{Conclusions}

Library provides people with spiritual nutrient so that people won't suffer from emotional starvation and have their own pursuits of life. The management and development of library can influence the overall quality of the whole nation. We should pay attention to its knowledge management and make qualified strategies and innovation. Different regions and different levels need different management systems. Managing indifferent ways and strategies can help develop knowledge management in library. We should connect this innovation with economic development of our society and realize the innovation in library management. Fulfilling knowledge management in library is along-term development target, which can't be finished in short time. It needs multiple reforms in managerial concept, managerial service and technologies.

Knowledge management in library will continue to develop, which will adjust to the society's development. It will devote to constructing new type library, satisfying people's spiritual pursuits and promoting the whole nation's knowledge level.

\section{References}

[1] Ji Baijian. Study on the Innovation of Library Management by Way of Knowledge Management. Office Business, 2013, (13). (in Chinese)

[2] Qiu Junping, Sha Yongzhong, Liu Huancheng. On Knowledge Management of Digital Library. 2008, (5). (in Chinese)

[3] Chen Hong. Try to study on the Innovation of Library Management by Way of Knowledge Management. Chizi, 2012, (4). (in Chinese)

[4] Zhong Yiya. Study on the Innovation of Library Management by Way of Knowledge Management. Overview of Worker Union, 2011, (5). (in Chinese)

[5] Zhou Qin. Study on the Innovation of Library Management by Way of Knowledge Management. Office Business, 2012, (21). (in Chinese)

[6] Yang Rong. Let Knowledge Management enter Library. Library work and Study, 2007, (3). (in Chinese)

[7] Wang Pin, Wang Qiang, Zhou Lixia. Study on Knowledge Management from the Perspective of Library and Information Science. Information and Resource, 2010, (3). (in Chinese)

[8] Zhang Futao. New Concept on Library knowledge Management. Library and Information, 2007, (2). (in Chinese)

[9] Ma Lingxia. Study on the Innovation of Library Management by Way of Knowledge Management. Guiding newspaper of Scientific and Techinical Innovation, 2013, (16). (in Chinese)

[10] Wang Wei. Study on the Innovation of Library Management by Way of Knowledge Management. Scientific and Technical Information of Heilongjiang Province, 2011, (17). (in Chinese) 